\title{
Beverage consumption and its associations with BMI and lifestyle factors in rural community participants
}

\author{
Roschelle Heuberger and Irene O’Boyle \\ Central Michigan University
}

\begin{abstract}
Beverages with little nutritional value, such as carbonated beverages, may negatively impact nutrition and have long-term health implications, including but not limited to obesity. This study examined the risks for beverage consumption choices and intake of participants living in a rural community. Multiple questionnaires adapted from the Chronic Illness Resources Survey, the Harvard Food Frequency Questionnaire, Michigan Alcohol Screening Test (MAST), the Alcohol Use Disorders Identification Test Questionnaire and 24 Hour Food Recall were administered to a cross sectional sample ( $\mathrm{n}=706)$ using trained interviewers. The mean age of participants was 23.67 years of age (SD +/- 7.32) with $49.7 \%$ females and $50.1 \%$ males. Results indicated that carbonated beverages and alcohol consumption were related to increased caloric intake and Body Mass Index (BMI) in the sample ( $p<0.05)$. Calories derived from carbonated beverages and alcohol consumption in younger persons (below age 35) exceeded ( $\mathrm{p}<$ $0.5)$ weight and age recommendations for intake as determined by the National Research Council. Older persons (34-53 and > 53 years old), both male and female, drank fewer carbonated beverages and consumed significantly $(\mathrm{p}<.05)$ more caffeinated beverages such as coffee, tea and hot chocolate. The study results suggest an increased need for research into beverage consumption and its relationship to BMI.
\end{abstract}

(c) 2009 Californian Journal of Health Promotion. All rights reserved.

Keywords: Beverage Consumption, Obesity, Nutrition, Rural

\section{Introduction}

The epidemic of obesity in the US represents a public health crisis and will continue to be one of the top public health challenges in the 21st century. Nutrition educators and public health officials alike have often pointed to the increased consumption of carbonated beverages as one of the major causes of obesity and other health problems (Bray, 2010). Experts have concluded that carbonated beverages displace other nutritious beverages and are hazardous to the cardiometabolic and lipid profiles of children, adolescents and adults (Bray, 2010; Bray 2008; vanDam \& Seidell, 2007). Several experts and community leaders have led the way for eliminating carbonated beverages from schools as a solution to reduce childhood obesity and dental caries. In 2007, Dhingra et al., reported that soft drink consumption in middle- aged adults is associated with a higher prevalence and incidence of multiple metabolic risk factors (Dhingra, Sullivan, Jacques, Wang, Fox, Meigs, D’Agostino, Graziano, Vasan, 2007).

"The weight of epidemiologic and experimental evidence indicates that greater consumption of sugar-sweetened beverages is associated with weight gain and obesity" (Malik, Schulze and $\mathrm{Hu}, 2006$, p. 274). In 2007, Wolff and Dansinger reported "Six of 15 cross-sectional and 6 of 10 prospective cohort studies identified statistically significant associations between soft drink consumption and increased body weight."

For the purposes of this study the researchers have defined carbonated beverages as drinks that are non-alcoholic, non-dairy and contain some amount of carbon dioxide $\left(\mathrm{CO}_{2}\right)$. 


\section{Trends in Obesity}

Research has established that the diet of many Americans is lacking in micronutrients, high in fat, low in fiber and high in calories, with only $10 \%$ of the nation having a nutrient dense, high quality dietary pattern (Miller, Drewnowski, Fulgoni, Heaney, King, and Kennedy, 2009). This type of diet includes the increased use of sweetened and carbonated beverages that provide calories without nutritional density (Storey, Forshee and Anderson, 2004). Increased sweetened carbonated beverage consumption has also been linked to dental caries and poor lifetime dentition and is important to overall nutrition (Moazzes, Smith, and Bartlett, 2000; Von Fraunhofer and Rogers, 2004). It is the consensus of the medical community that the trend in carbonated beverage consumption among Americans is a major public health issue (Bray, 2010). Guidelines provided from the scientific community for prevention of obesity and cariogenesis include decreasing carbonated beverage consumption (Von Fraunhofer and Rogers, 2004).

\section{Trends in Beverage Intakes in the US}

This research study was undertaken to supplement the existing body of evidence regarding beverage consumption and BMI in rural communities, which were otherwise unaccounted for in the literature. In 2007 the American Journal of Public Health published a meta analyses of 88 studies that examined the association between carbonated beverage consumption and nutrition and health outcomes. That meta analyses found a clear association of carbonated beverage intake with increased energy intake and body weight. The higher carbonated beverage intake was also associated with lower intakes of milk, calcium and other nutrients and an increased risk for several medical problems (e.g. diabetes), (Vartanian, Schwartz and Brownell, 2007). These researchers recommended decreases in carbonated beverage consumption. They concluded that carbonated beverages offer energy with little accompanying nutrition, displace other nutrient sources and are linked to several key health conditions such as diabetes. These issues can be used as further impetus to recommend a reduction in carbonated beverage consumption (Vartanian, et al., 2007). Nielsen and Popkin reported in 2005 that changes in beverage consumption increased as a percentage of total energy between 1977 and 2001. The researchers reported that there were two welldocumented trends: "...a decrease in milk consumption and an accompanying increase in sweetened beverages" (Nielsen and Popkin, 2005, p. 413).

Beverage consumption trends among both children and adults have changed dramatically over the past three decades. Increased consumption of carbonated beverages has been associated with reductions in bone mass, dental caries, obesity and overall poor dietary quality (Frary, Johnson and Wang, 2004). Increased consumption of supplemental "energy drinks", herbal and fortified drinks may also pose health risks due to potential interactions of these compounds with nutrients (Stedman, 2002). Historically, information on diet, particularly carbonated beverage consumption, and BMI has been limited when studying the associations with obesity (Tsiros, Sinn, Brennan, Coates, Walkeley, Petkov, Howe, and Buckley, 2008). This study will add to the existing literature by confirming findings from Vartanian et al. and Fray et al. This study will assist with understanding beverage consumption habits of adults especially in rural populations.

\section{Nutrient Content in Beverages}

Sweetened carbonated beverage consumption can provide oral bacteria with a ready source of nutrients. The bacteria metabolize the sugars and excrete acids which alter the $\mathrm{pH}$ in the mouth resulting in erosion of tooth enamel and subsequent caries, root exposure and tooth loss (Gedalia, Ionat-Bendat, Ben-Moshehi, and Shabira, 1991). Oral health is related to cardiometabolic disease risks and bacterial proliferation in the oral cavity has been associated with cardiovascular disease along with obesity (Heller, Burt and Ekland, 2001). Bacterial colonization can result in the systemic entrance of bacteria into the bloodstream. This can result in systemic diseases and has been linked to atherosclerotic changes and plaque buildup in blood vessels in adults (Shay, 2002). Increased consumption of sugars results in 
increased oral bacterial burden and Guthrie and Morton in 2000, reported that the largest source of added sweeteners were regular soft drinks, which accounted for one third of daily caloric intakes. They concluded that intake of added sweeteners exceed levels compatible with meeting current dietary recommendations and impact overall health risk (Guthrie and Morton, 2000).

\section{Beverage Intakes and Health Consequences}

In 2006, Malik et al. reported a positive association between greater intakes of sugar sweetened beverages and weight gain and/or obesity in both children and adults (Malik, Schulze, $\mathrm{Hu}, 2006)$. In 2008, Bray reported that evidence suggested that we should worry about our current level of fructose consumption, which has been increasing steadily for over 200 years and now represents over $10 \%$ of the energy intake of some people. "Adults who drink soda occasionally (not every day) are 15\% more likely to be overweight or obese, and adults who drink one or more sodas per day are $27 \%$ more likely to be overweight or obese than adults who do not drink soda, even when adjusting for poverty status and race/ethnicity" (Babey, Jones, and Goldstein, 2009 p. 1).

The use of carbonated beverages, alcohol and caffeinated "energy" drinks has been implicated in adverse events such as dehydration in addition to obesity (Clauson, Sheilds, McQueen, \& Persad, 2008). Alcohol, caffeine, guarana, simple carbohydrates, excessive sodium and phosphoric acid content decreases hydration by a combination of direct diuretic effects on the kidney and cellular cation/anion exchange as was first discussed by Rodgers in 1999 . Dehydration and electrolyte imbalance from the excessive use of these compounds is of concern, especially in environmental extremes of temperature and during physical activity and complicates health risk in obese persons (Klein, 1999).

\section{Research Purpose}

There is a limited amount of research in rural populations on this subject matter. This provides significant challenges for health educators where education plays a major role for the general public and requires collaboration with many individuals in the health care system. Rural populations, particularly those with lower socioeconomic standing are at heightened risk for obesity related complications. The purpose of this study was to determine beverage consumption and its association with BMI and lifestyle factors in rural community residents to ascertain the need for intervention and/or the development of appropriate health education messages and materials.

\section{Methods}

\section{Study Design and Sample Population}

A quantitative, non-experimental, cross sectional design was used to evaluate beverage consumption and its point prevalence with respect to health impact on rural community dwellers. The study is not causally determinant and was undertaken to justify future continued, longitudinal research in this arena. The Institutional Review Board/Human Subjects Committee at the primary institution approved this project. Informed consent was obtained from all participants and no identifying information was associated with the participants' responses. Participants reviewed the consent form(s) with the interviewer and statements regarding subject anonymity, data confidentiality and data access were provided.

A convenience sample of community participants $(n=706$, age range from 17-72 years) living in rural Michigan were recruited. The term rural is defined by the US Census as a geographic area outside the urban areas or urban clusters (US Census, 2010). Potential subjects were recruited from community functions, fairs, athletic events, local organization meetings, and the sorority and fraternity systems on the local university campus, along with grocery stores and other public venues. Participants were required to be over the age of 17 years and able to provide informed consent. There were no other exclusion criteria since the interviewers did not assess health and all participants completing the survey were included. Participants were enrolled in an ongoing fashion until the sample size target was reached. This target was calculated using pilot data. Recruitment was accomplished 
using flyers on approximately 30 kiosks in stores, the university campus, town parks and town squares. The interviewers also distributed flyers to participants at various locations throughout the town and surrounding counties. Some of the neighboring counties included some of the poorest rural areas in Michigan. Interviewers were able to engage participants in conversations associated with the study, and distributed announcements and classified ads in student newspapers and senior news publications over an 18-month period of time. Because of the type of recruitment it is possible that some individuals may have been excluded from the study and this is a possible limitation. Participants were recruited voluntarily without any compensation or incentive to participate in this survey regarding their health, lifestyle and beverage consumption. The principle investigator trained the five interviewers. The funding for this study was acquired by internal grants from the sponsoring institution.

\section{Measures and Data Collection}

The instruments used were standard health and lifestyle questionnaires adapted from the Chronic Illness Resources Survey, Harvard Food Frequency Questionnaire (FFQ), Michigan Alcohol Screening Test and Alcohol Use Disorders Identification Test and 24 Hour Food Recall, for food, alcohol and beverage intake (Gibson, 1990). The Chronic Illness Resources Survey is a 36-item survey with a mean reliability co-efficient alpha $=0.85$. The FFQ is a 160 line item survey with a reliability coefficient of alpha $=0.77$ (Gibson, 1990). The Michigan Alcohol Screening Test (MAST) is a binary 24 item survey with a reliability coefficient of 0.83 while the Alcohol Use Disorders Identification Test is a 10 item binary survey with a reliability co-efficient of alpha $=0.81$. The 24 Hour Food Recall is an open-ended survey with a reliability alpha coefficient of 0.80 (Willett, 1990). The interviews took approximately one hour. Trained interviewers were able to decrease the errors associated with obtaining information on diet, lifestyle and beverage consumption through repeated mock practice sessions conducted by the principle investigator (Glasgow, Toobert, Barrera \& Strycker, 2005). The FFQ items were selected on the basis of their quantification of beverage consumption. The FFQ is a standard epidemiological technique for food and beverage pattern assessment (Slesinski, Subar, \& Kahle, 1996). Alcohol consumption was also assessed in this manner (McCann et. al, 1999). Inter-rater reliability between interviewers who piloted the questionnaires was high at $\mathrm{r}=0.93$ for the same questions asked by different interviewers to the same participant on different days. Participants were assessed regarding beverage consumption for carbonated beverages, alcohol, caffeinated beverages and energy drinks.

Open-ended questions were coded sequentially in order of appearance and grouped by class in quintiles. Other lifestyle factors were included to elucidate any confounding that may have resulted from drug-nutrient, environmental, lifestyle and disease-nutrient associations. Smoking history, drug or medication use, supplement use, herbal preparation use and any disease diagnoses were also obtained through open ended inquiry. Demographic information collected included age, race, marital status and gender.

The participants Body Mass Indices (BMI) were calculated by the interviewers using selfreported height and weight. BMI was categorized according to the current guidelines for adult underweight (Hassan, Joshi, Madhavan \& Amonkar, 2003) $(<18)$, normal weight $(18-$ $25)$, overweight (25-30) and obese (>30). Morbid obesity (BMI >40) was included in the obese category due to dearth of participant who were classified as such (Aronne, 2002). Beverage intake was classified as light versus heavy based on median levels of intake.

Nutrient composition for classes of beverages (such as artificially sweetened caffeinated cola, caffeinated beverages such as coffee, tea or hot chocolate, etc.), were determined using the Nutritionist Pro Software System ${ }^{\circledR}$, v 3.0, San Bernadino, CA, 2004 and the manufacturer's data. Data were entered, cleaned, coded and conditioned in Microsoft Excel 2007, Microsoft Corporation, Seattle, WA 2007-2010. Data was transferred and analyzed using SPSS version 16.0 Statistical Software Package for the Social 
Sciences Inc. Charleston, N. C. The analyses are discussed below.

\section{Statistical Analyses}

Statistical analyses of the data included both parametric and non-parametric measures. Descriptive statistics, correlation measures, and cross comparison tests were also used. It is well known that the variability of intake among individuals' first time reporting of past dietary recall is a limitation in epidemiological nutritional research. This can be stemmed by increasing sample sizes and limiting recommendations to groups rather than individuals (Radimer, Subar \& Thompson, 2000). Logistic regression was performed on binomial variables and potentially contributory categorical data such as race and gender. The levels of alcohol consumption were also investigated.

An analysis of potential confounding was undertaken by the use of Maximum Likelihood Testing procedures for any of the logistic regressions performed (Greenland, 1993). Tukey's T-testing for the independent group variables based on age were used to ascertain significance levels between amount of carbonated beverages consumed, amount of caffeinated beverages consumed and amount of alcoholic beverages consumed by age and gender group. Multiple significance testing was amended by the use of the Bonferroni multiple testing correction. Chi-Square analyses were undertaken for gender groupings for amount of carbonated beverages consumed, amount of caffeinated beverages consumed and amount of alcoholic beverages consumed. Linear regression analyses were undertaken for the contribution of age and carbonated beverages consumed, amount of caffeinated beverages consumed and amount of alcoholic beverages consumed to BMI. Logistic regressions were undertaken to analyze the contribution of age, gender, level of carbonated beverages consumed, amount of caffeinated beverages consumed and amount of alcoholic beverages consumed to $\mathrm{BMI}(\leq 25,>25)$.

\section{Results}

\section{Subject Characteristics}

The demographics for this sample are presented in Table 1. Many of the respondents were single and college age due to the primary recruitment site being in a college town, although other sites were used and reflected the rural demographics. The vast majority (92\%) of respondents were Caucasian, which is representative of the rural geographic area where the recruitment took place. Factors such as smoking and alcohol use impacted choice and level of beverage consumption in this sample. The results are depicted in Table 1. Most participants in the study consumed alcohol and carbonated beverages, and there were insufficient numbers of abstainers (1\% or 8 participants out of 706 ) to investigate differences between drinkers and non-drinkers.

Eighty-six percent of the survey sample reported consuming carbonated beverages, half of which were consuming these beverages at a level of moderate intake or higher. High intake is defined at $>58$ ounce servings per day and moderate intake is defined at 4 eight ounce servings of the beverage per day. Drinkers of artificially sweetened carbonated beverages reported an intake of approximately $1000 \mathrm{mg}$ of non-nutritive sweetener on a weekly basis, in addition to caffeine and phosphorus. Light intake, which was defined as less than 4 eight ounce servings of carbonated beverages consumed per day, resulted in approximately 87 $\mathrm{mg}$ of non-nutritive sweetener being consumed weekly. Gender differences were observed in total consumption of ethanol, with men consuming on average 18 drinks per week and women consuming approximately 10 drinks per week.

\section{Beverage Consumption}

Beverage consumption by level of intake, refined carbohydrate intake and age are presented in Table 2. Refined carbohydrate was defined as simple carbohydrates obtained from the beverages consumed, and those included 
Table 1

Demographic and lifestyle characteristics of rural participants $(n=706)$

\begin{tabular}{ll}
\hline Age & \\
Mean \pm SD & $23.67 \pm 7.32$ \\
Minimum, Maximum & 17,72 \\
\hline Gender & \\
Female & $49.7 \%$ \\
Male & $50.1 \%$ \\
\hline Race & \\
Caucasian & $92.2 \%$ \\
African American & $3.4 \%$ \\
Hispanic & $1.0 \%$ \\
Other & $1.6 \%$ \\
\hline Marital Status & \\
Single & \\
Married & $90.4 \%$ \\
Divorced & $7.2 \%$ \\
Other & $0.71 \%$ \\
\hline Smoking Status & $0.85 \%$ \\
Current & \\
Never, Former & \\
\hline Alcohol Consumption Status & \\
Current Drinker & \\
Never, Abstainer & \\
\hline Carbonated Beverage Consumption & \\
Status & \\
Current Drinker & \\
Non Drinker & \\
\hline Caffeinated Beverage (Excluding & \\
Carbonated) Consumption Status & \\
Current Drinker & \\
Non Drinker & \\
\hline & \\
& \\
\hline
\end{tabular}

sugar sources such as sucrose, high fructose corn syrup, malto-dextrins and other simple sugars These do not include refined carbohydrates from other sources such as fruit juices. The categories were determined based on standardized serving sizes which are defined as 8 ounces of liquid. Body Mass Indices were analyzed across gender and age groups. Body Mass Indices are derived from a power calculation based on height and weight. Males typically have greater heights, which standardizes the BMI between genders. In addition, genders were equally distributed across age groups with approximately half the sample being male and half being female allowing for data collapse across groupings.

Older persons showed differences in the level of beverage consumption and beverage choice than their younger counterparts. Older persons, both male and female, drank fewer carbonated beverages and consumed significantly more caffeinated beverages such as coffee, tea, and hot chocolate. For all participants' coffee, tea, and hot chocolate consumption showed an inverse relationship for BMI at a level of $\mathrm{p}<$ 0.15 , however statistical significance was not achieved. Caffeinated beverages, excluding carbonated beverages, were inversely associated with BMI (using activity level as a controlling variable) in women at levels of $\mathrm{p}<0.08$ evidencing a trend towards decreased BMI with heavier caffeine use. Refined carbohydrate intake from beverages was significantly lower in older participants than younger.

In a multivariate regression model, age and refined carbohydrate intake from carbonated beverages were significantly associated in a positive manner with BMI at $p<.001$ and $p<.05$ respectively. BMI was controlled by activity level. Caloric density was not controlled because caloric density in beverages is comparable to beverage refined carbohydrate levels. 
Table 2

Percent carbonated beverage consumption and grams refined carbohydrate contained therein by level of intake and age $(n=706)$

\begin{tabular}{lccccc}
\hline \multicolumn{1}{c}{ Category } & $\mathbf{1 7 - 1 9}$ years & $\mathbf{2 0 - 2 2}$ years & $\mathbf{2 3 - 3 3}$ years & $\mathbf{3 4 - 5 3}$ years & $>\mathbf{5 3}$ years \\
\hline $\begin{array}{l}\text { \% Low } \\
\text { (<Four 8 oz. servings/ day) }\end{array}$ & $70.2 \%$ & $68.1 \%$ & $69.0 \%$ & $74.4 \%$ & $75.6 \%$ \\
\hline $\begin{array}{l}\text { \% High } \\
\text { (>Four 8 oz. servings/ day) }\end{array}$ & $29.8 \%$ & $31.9 \%$ & $31.0 \%$ & $25.6 \%$ & $24.4 \%$ \\
\hline $\begin{array}{l}\text { Refined Carbohydrates } \\
\text { (grams/ day) }\end{array}$ & 295 & 279 & 309 & 178 & 217 \\
\hline
\end{tabular}

${ }^{\mathrm{a}}$ Refined carbohydrate includes sugar, dextrose, HFCS, \& sucrose

Table 3

Mean \pm SD Carbonated beverage, alcoholic beverage, and caffeinated beverage consumption in 8 ounce servings across Body Mass Index (BMI) category $(\mathrm{n}=706)$

\begin{tabular}{lllllll}
\hline \multicolumn{1}{c}{ Beverage } & \multicolumn{2}{c}{ BMI $<25$} & & \multicolumn{2}{c}{ BMI 25-30 } & \multicolumn{2}{c}{ BMI > 30 } \\
& Mean & SD & Mean & SD & Mean & SD \\
\hline $\begin{array}{l}\text { Carbonated beverages } \\
\text { (8 oz. servings) }\end{array}$ & $0.94^{\mathrm{a}}$ & 1.1 & $1.1^{\mathrm{b}}$ & 1.25 & $1.43^{\mathrm{a}, \mathrm{b}}$ & 1.65 \\
\hline $\begin{array}{l}\text { Alcohol } \\
(8 \text { oz. servings) }\end{array}$ & 1.67 & 1.68 & 1.94 & 1.94 & 1.70 & 2.11 \\
\hline $\begin{array}{l}\text { Caffeinated tea, coffee } \\
(8 \text { oz. servings) }\end{array}$ & $0.16^{\mathrm{a}}$ & 0.50 & $0.19^{\mathrm{b}}$ & 0.58 & $0.35^{\mathrm{a}, \mathrm{b}}$ & 0.96 \\
& & & & & & \\
\hline
\end{tabular}

${ }^{\mathrm{a}}$ Statistically significant difference versus BMI $<25$ using T-tests $(\mathrm{p}<.05)$

${ }^{\mathrm{b}}$ Statistically significant difference versus BMI $25-30$ using T-tests $(\mathrm{p}<.05)$

Anthropometry and levels of beverage consumption are depicted in Table 3. Age correlated with an increase in BMI among participants, paralleling trends in the national data (Flegal \& Troiano, 2000). Pearson correlations showed that BMI was significantly related to the number of carbonated beverages (diet and regular) drank per week by participants ( $p<.002 ; 2$-tailed). Level of alcohol intake was compared to BMI and was significantly associated with BMI at a level of $\mathrm{p}<0.009$. Results for the correlation were significant for a 2-tailed comparison. In participants aged 17 to 19 , the number of alcoholic drinks per week was significantly associated with high BMI at a level of $\mathrm{p}<.001$ using a step-wise regression analyses. Alcohol intake was also statistically significant as a predictor of BMI for those ages 20 to 22 at a level of $\mathrm{p}<.02$.

Levels of kilocalories and phosphorus are shown by age classification and gender in Table 4 . Calories from carbonated beverages were positively associated with BMI for all participants at a trend level of $\mathrm{p}<.10$ using stepwise regression controlled for age, smoking, alcohol intake, medication and supplement use. In the youngest participants, calories from carbonated beverage intake suggested a trend toward increasing BMI at a level of $\mathrm{p}<.06$ for 
those aged 17 to 19 . Figure I depicts the relationship between carbonated beverage consumption, age, and BMI in bar graph format.

There were differences in beverage consumption based on age in this cross sectional sample of rural participants. Persons over the age of 35 had greater levels of intake for caffeinated beverages than their younger counterparts and this was associated with decreasing BMI at the highest levels of caffeine consumption. Younger persons drank more carbonated sweetened beverages than their older counterparts ( $>35$ years) and this contributed significantly to BMI in this sample $(\mathrm{p}<.01)$. BMI was positively associated with increasing carbonated beverage consumption as it was with increasing alcoholic beverage consumption. Males and females were equally distributed amongst age groupings and data were analyzed both by gender as well as across gender by age. Kilocalorie intake rose with increasing carbonated beverage consumption as

Table 4

Mean \pm SD kilocalories (kcals), phosphorus (mg) and caffeine (mg)

from carbonated beverages consumed by age category and gender $(n=706)$

\begin{tabular}{|c|c|c|c|c|}
\hline & \multicolumn{4}{|c|}{ Age Categories (years) } \\
\hline Females & $17-19^{a}$ & $20-22^{b}$ & $23-33^{c}$ & $>34^{a, b, c}$ \\
\hline Kcals \pm SD & $739 \pm 993$ & $558 \pm 865$ & $786 \pm 1252$ & $399 \pm 1016$ \\
\hline Phosphorus \pm SD & $278 \pm 367$ & $262 \pm 344$ & $311 \pm 390$ & $250 \pm 294$ \\
\hline Caffeine \pm SD & $268 \pm 316$ & $276 \pm 346$ & $305 \pm 343$ & $382 \pm 500$ \\
\hline \multicolumn{5}{|l|}{ Males } \\
\hline Kcals \pm SD & $1435 \pm 1697$ & $1369 \pm 1799$ & $1277 \pm 1724$ & $532 \pm 1424$ \\
\hline Phosphorus \pm SD & $346 \pm 575$ & $333 \pm 525$ & $371 \pm 647$ & $299 \pm 470$ \\
\hline Caffeine \pm SD & $396 \pm 481$ & $401 \pm 533$ & $414 \pm 531$ & $458 \pm 781$ \\
\hline
\end{tabular}

$a, b, c$ Statistically significant difference between groups and across gender $(p<.05)$

well as with alcoholic beverage consumption and this was positively associated with increasing BMI $(\mathrm{p}<.05)$. The same was true of refined carbohydrates and phosphorus, both of which are components of carbonated beverages such as sweetened colas $(\mathrm{p}<.05)$.

\section{Discussion}

This study investigated the contributions of beverages to BMI and nutritional status in rural participants. The findings contribute to the existing body of literature regarding beverage consumption and its impact on obesity and health in the U.S. The investigators found direct relationships between increased carbonated beverage consumption and BMI across age and gender. The research also points to an inverse relationship between heightened caffeine consumption from coffee, tea etc. in older persons and BMI. Components in carbonated beverages such as refined carbohydrates and phosphorus also evidenced direct relationships to BMI in younger adults.

During the past decades many researchers have concluded that it is essential that pediatricians, nurses, dietitians and health educators continue to work with community leaders and parents to address the obesity epidemic (Marr, 2004; Marshall, et al. 2003). "The percentage of overweight in the United States and other countries has now reached epidemic proportions." (Marr, 2004, p. 258). "Longlasting solutions to the obesity epidemic must be comprehensive and include all of the key stakeholders (Marr, 2004, p. 258). Nutrition educators can play a key role in developing 
wide-ranging and diverse coalitions, which include food and beverage companies, designed to affect social change aimed at achieving healthy weight.

\section{Limitations and Implications of the Study}

The results of this study suggest an increased need for research into beverage consumption as well as an increased need for education regarding the potential for long-term consequences on health. Further studies should attempt to ascertain the extent of displacement of nutrients by increased carbonated beverage consumption, the trends in beverage consumption from a nationally representative sample and the prospective impact of nonnutritive beverages on health in later life. The limitations of the present research include the cross-sectional nature of the investigation, inability to ascertain causality, the inability to track changes and predict health risk over time and inability to investigate longitudinal issues. In addition, because height and weight were not measured using a scale or stadiometer, BMI was a calculated value based on self-reported data. This is a limitation due to weight underreporting and height over-reporting. It should be noted however, that this combination of under and over-reporting has been seen in much of the literature that investigates BMI and nutrition epidemiologically and is considered to be acceptable.

These results, while not generalizable to the population of the U.S. as a whole, do point to an increased need to continue this research with a greater, more representative sampling of urban and rural areas. This lack of generalizabilty is due to the diversity within US's standardized regions (urban, suburban, semi-rural, rural) and our sample was not racially or ethnically diverse. The Midwest, and specifically our rural composition, is unlike many other areas within the US and the fact that our sample was definitively rural is not representative of national distributions, as rural areas are fewer and far between. Rural distributions are also less studied, more difficult to study and fraught with greater challenges in terms of participant recruitment, retention and availability. The findings do however identify the need for increased nutrition education regarding beverage consumption. Alcohol/ethanol intake in this particular sample was quite high. The average energy obtained from the intake of ethanol containing beverages was estimated to be 1554 kcals per week. Given that alcoholic beverages are usually "empty calories" it may be a significant contributor to elevated BMI and potentially damaging to long-term health. (Kerr, Greenfield, Bond, Ye \& Rehm, 2004).

Improved nutritional status is associated with better overall health status, fewer office visits and lower health care service expenditures. Consumption habits have lifelong implications on health and well-being, but the acute effects of poor consumption patterns are also evident. Metabolic syndrome is becoming evident in persons of younger ages, with the rise in obesity. (Weiss et. al, 2004; Eisenmann, 2003). Rural communities will be well served by trying to stem the consequences of the obesity epidemic through nutrition and beverage educational campaigns. Primary prevention is important from a cost benefit standpoint in addition to the obvious other benefits. The benefits include, but are not limited to, a decrease in morbidity and mortality in the future, lower costs of health care, shorter hospital stays, less utilization of emergency rooms as primary provider points of service for the underinsured or uninsured and increased percentages of persons who are aging successfully.

To start, the policy and theoretical implications for rural communities could be focused in many ways, including movements to ban vending machines which only stock non-nutritive selections, improving the dissemination of nutrition information to this population through community classes, health promotion programs at community hospitals or health centers or through health fairs and other health initiatives. Because these issues are of great interest to health professionals, routine inquiries into beverage consumption patterns should be conducted with patients at every visit. Educational materials should be made available for these encounters and reinforcing messages delivered when patients are present for routine examinations. In addition, faculty at rural 
college campuses could focus on an introductory nutrition course as a general education requirement for incoming students, or the inclusion of this information into existing health courses, general science courses or orientation programs. Community wide health advocacy representatives should become educated regarding the possibilities of the negative impact of current trends in beverage consumption. Dining establishments could provide nutritional information for patrons, and an effort should be made to include beverage information as well.
Community health campaigns and fraternal health societies may also be a venue for the dissemination of nutrition-related information regarding beverage consumption. The results of this study could provide an opportunity for discussion for health education professionals in all disciplines to work together to impact the overall health outcome of communities. Health educators will also want to address beverage consumption in the context of behavior change strategies.

\section{References}

Aronne LJ. (2002). Classification of obesity and assessment of obesity-related health risks. Obesity Research, 10(Suppl 2), S105-S115.

Babey, S.H., Jones, M. \& Goldstein, H. (2009). Bubbling over: soda consumption and its link to obesity in California. Policy brief (UCLA Center for Health Policy Research) (Policy Brief UCLA Center Health Policy Res). Sept. (PB2009-5),1-8.

Bray, G.A. (2008). Fructose: should we worry? International Journal of Obesity, 32 Suppl 7 , S127-S131.

Bray, G.A. (2010). Soft drink consumption and obesity: it is all about fructose. Current Opinions in Lipidology, 21, 51-7.

Clauson, K.A., Sheilds, K.M., McQueen, C.E., \& Persad, N. (2008). Safety Issues associated with commercially available energy drinks. Journal of the American Pharmacists Association, 48, e55-e63.

Dhingra, R.; Sullivan, L.; Jacques, P.F.; Wang, T.J.; Fox, C.S.; Meigs, J.B.; D’Agostino, R.B.; Graziano, J.M. \& Vasan, R.S. (2007). Soft drink consumption and risk of developing cardiometabolic risk factors and the metabolic syndrome in middle-aged adults in the community. Circulation, 116, 480-8.

Eisenmann, J. C. (2003). Secular trends in variables associated with the metabolic syndrome of North American children and adolescents: A review and synthesis. American Journal of Human Biology, 15, 786-794.

Flegal, K.M., \& Troiano, R.P. (2000). Changes in the distribution of Body Mass Index of adults and children in the US population. International Journal of Obesity and Related Metabolic Disorders, 24, 807-818.

Frary, C. D., Johnson, R. K., \& Wang, M. Q. (2004). Children and adolescents' choices of foods and beverages high in added sugars are associated with intakes of key nutrients and food groups. Journal of Adolescent Health, 34, 56-63.

Gedalia, I., Ionat-Bendat, D., Ben-Mosheh, S., and Shapira, L. (1991). Tooth enamel softening with a cola type drink and rehydrating with hard cheese or stimulated saliva in situ. Journal of Oral Rehabilitation, 18, 501-506.

Gibson, R.S. (1990). Principles of Nutritional Assessment. Oxford University Press. NY. NY. Glasgow, R, Toobert, D.J., Barrera M, \& Strycker L.A. (2005). The Chronic Illness Resources Survey: A cross-validation and sensitivity to intervention. Health Education Research, 20, 402-9. 
Greenland, S. (1993). Methods for epidemiologic analyses of multiple exposures: A review and comparative study of maximum likelihood, preliminary testing and empirical Bayes regression. Statistics and Medicine, 12, 717-736.

Guthrie, J. F. \& Morton, J.F. (2000) Food sources of added sweeteners in the diets of Americans. Journal of the American Dietetic Association, 100, 43-51.

Hassan, M. K., Joshi, A. V., Madhavan, S. S., \& Amonkar, M. M. (2003). Obesity and healthrelated quality of life: a cross-sectional analysis of the US population. International Journal of Obesity and Related Metabolic Disorders, 27, 1227-1232.

Heller, K.E., Burt, B.A. \& Eklund, S.A. (2001). Sugared soda consumption and dental caries in the US. Journal of Dental Research, 80, 1949-1953.

Kerr, W. C., Greenfield, T. K., Bond, J., Ye, Y., \& Rehm, J. (2004). Age, period and cohort influences on beer, wine and spirits consumption trends in the US National Alcohol Surveys. Addiction, 99, 1111-1120.

Klein, S. M. (1999). Water: an essential but overlooked nutrient. Journal of the American Dietetic Association, 99, 200-206.

Malik, V.S.; Schulze, M.B. \& Hu, F.B. (2006). Intake of sugar-sweetened beverages and weight gain: a systematic review. American Journal of Clinical Nutrition, 84, 274-88.

Marr, L. (2004). Sodas, childhood overweight, and the role of nutrition educators: Let's base our solutions on reality and sound science. Journal of Nutrition Education and Behavior, $36,258-265$.

Marshall, T.A., Levy, S.M., Broffitt, B., Warren, J.J., Eichenberger-Gilmore, J.M., Burns, T.L. \& Stumbo, P.J. (2003). Dental caries and beverage consumption in young children. Pediatrics, 112, 184-191.

McCann, S.E., Marshall, J.R., Trevisan, M., Russell, M., Muti, P., Markovich, N., Chan, A.W., \& Freudenheim, J.L. (1999). Recent alcohol intake as estimated by the Health Habits and History Questionnaire, the Harvard Semi-Quantitative Food Frequency Questionnaire, and a more detailed alcohol intake questionnaire. American Journal of Epidemiology. 150, 334-340.

Miller, G.D., Drewnowski, A., Fulgoni, V., Heaney R.P., King, J., \& Kennedy, E. (2009). It is time for a positive approach to dietary guidance using nutrient density as a basic principle. Journal of Nutrition, 139, 1198-1202.

Moazzes, R., Smith, B. G., \& Bartlett, D. W. (2000). Oral pH and drinking habit during ingestion of a carbonated drink in a group of adolescents. Journal of Dentistry, 28, 395-397.

Nielsen, S.J. \& Popkin, B.M. (2005). Changes in beverage intake between 1977 and 2001. American Journal of Preventive Medicine, 28, 413.

Radimer, K. L., Subar, A. F., \& Thompson, F. E. (2000). Nonvitamin, nonmineral dietary supplements: issues and findings from NHANES III. Journal of the American Dietetic Association, 100, 447-454.

Rodgers, A. (1999). Effect of cola consumption on urinary biochemical and physiological risk factors associated with calcium oxalate urolithiasis. Urology Research, 27, 77-81.

Shay. K. (2002) Infectious complications of dental and periodontal diseases in the elderly population. Clinical Infectious Diseases, 34, 1215-1223.

Slesinski, M. J., Subar, A. F., Kahle, L. L. (1996). Dietary intake of fat, fiber and other nutrients is related to the use of vitamin and mineral supplements in the United States: the 1992 National Health Interview Survey. Journal of Nutrition, 126, 3001-3008.

Stedman, C. (2002). Herbal hepatotoxicity. Seminars in Liver Disease, 22, 195-206. 
Storey, M.L., Forshee, R.A., \& Anderson, P.A. (2004). Associations of adequate intake of calcium with diet beverage consumption and demographic characteristics. Journal of the American College of Nutrition, 23, 18-33.

Tsiros, M.D., Sinn, N., Brennan, L., Coates, A.M., Walkley, J.W., Petkov, J., Howe, P, R.C., \& Buckley, J.D. (2008). Cognitive behavioral therapy improves diet and body composition in overweight and obese adolescents. American Journal of Clinical Nutrition, 87, 11341140.

US Census (2010). http://www.census.gov/geo/www/ua/ua_2k.html retrieved on February 25, 2010.

vanDam, R.M. \& Seidell, J.C. (2007). Carbohydrate intake and obesity. European Journal of Clinical Nutrition, 61 (Suppl 1), S75-S99.

Vartanian, L.R., Schwartz, M.B. \& Brownell, K.D. (2007). Effects of soft drink consumption on nutrition and health: A systematic review and meta-analysis. American Journal of Public Health, 97, 667-675.

Von Fraunhofer, J.A., \& Rogers, M.M. (2004). Dissolution of dental enamel with soft drinks. General Dentistry, 52, 308-312.

Weiss, R., Dziura, J., Burgert, T. S., Tamborlane, W. V., Taksali, S. E., Yeckel, C. W., Allen, K., Lopes, M., Savoye, M., Morrison, J., Sherwin, R. S., \& Caprio, S. (2004). Obesity and the metabolic syndrome in children. New England Journal of Medicine, 350, 2362-2374.

Wolff, E. \& Dansinger, M.L. (2007). Soft drinks and weight gain: how strong is the link? Medscape Journal of Medicine, 10, 189.

Willett, W. (1990) Nutritional Epidemiology. Oxford University Press. NY, NY.

$\underline{\text { Author Information }}$

Roschelle A Heuberger, Ph.D., R.D.*

Associate Professor

Central Michigan University

106A Wightman Hall

Mt. Pleasant, MI 48859

Phone: 989-774-3571

Facsimile: 989-774-2435

Email: heube1ra@cmich.edu

Irene O'Boyle, Ph.D., CHES

Associate Professor

Central Michigan University

* corresponding author 
Appendix A

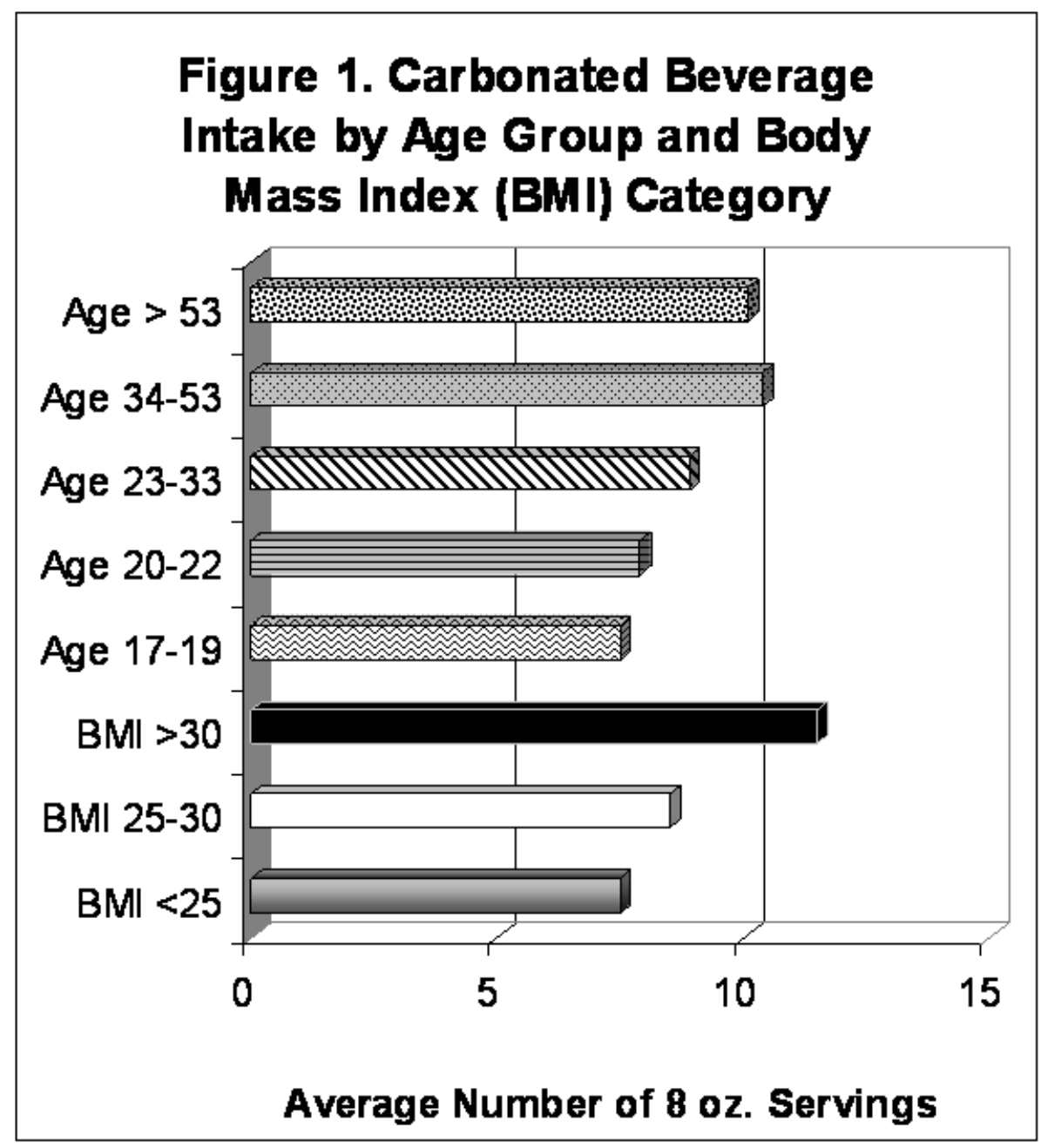

